\title{
NARRATIVAS E REPRESENTAÇÕES SOBRE OS SURDOS EM TECNOLOGIAS VIRTUAIS: análise videográfica no site do youtube®
}

\author{
Kátia do Socorro Carvalho Lima' \\ Ivanilde Apoluceno de Oliveira ${ }^{2}$ \\ Igor Belo dos Santos 3
}

\begin{abstract}
RESUMO
O artigo em questão tem como objetivo analisar as narrativas contidas em diferentes tipos de vídeos brasileiros postados no site do YouTubeß, que falam sobre os sujeitos Surdos com atenção as representações veiculadas sobre eles, se estão fundamentadas em narrativas da diferença ou da incapacidade. A abordagem do estudo é qualitativa e, se constitui de uma pesquisa exploratória, por meio da análise documental de 08 vídeos, selecionados a partir da busca na internet, com o uso do termo "surdo mudo", no dia 12 de julho de 2019, sendo encontrados 543 vídeos relacionados com o termo de busca, com diferentes datas de postagens, referentes ao período de 2018 e 2019, destes 204 apresentavam no título o termo "surdo mudo", que categorizamos como vídeos de contexto religioso, de piadas, e de reportagens. Dos resultados, posterior as análises, observa-se que as narrativas sobre os Surdos são fundamentadas numa representação da surdez como doença e os Surdos como pessoas incapazes.
\end{abstract}

Palavras-chave: Narrativas. Representações. Surdos. Tecnologia virtual.

\footnotetext{
1 Doutoranda em Comunicação, Linguagens e Cultura - Universidade da Amazônia UNAMA; Mestre em Educação pela Universidade do Estado do Pará. Docente da Universidade do Estado do Pará. Professora do Centro Universitário FIBRA. Pesquisadora do Núcleo de Educação Popular Paulo Freire/UEPA e do Grupo de Estudos e Pesquisa Interdisciplinares em Diversidade e Inclusão/UNAMA. Brasil. Orcid: https://orcid.org/000000001-9163-1956. E-mail: katiasclima@gmail.com

2 Pós-doutora em Educação pela PUC-Rio. Doutora em Educação pela PUC-SP e UNAM/UAM Iztapalapa - México. Docente do Programa de Pós-Graduação em Educação da Universidade do Estado do Pará. Coordena o Núcleo de Educação Popular Paulo Freire e a Cátedra Paulo Freire da Amazônia. Brasil. Orcid: https://orcid.org/0000-0002-3458-584X. Email: ivanildeapoluceno@vepa.br

3 Bolsista do CNPq - Brasil. Mestrando em Educação na Universidade do Estado do Pará (UEPA) pelo Programa de Pós-Graduação em Educação - PPGED. Pós-Graduação Latu Sensu em Educação Especial com Ênfase na Inclusão pela Faculdade Integrada Brasil Amazônia. Pesquisador do Grupo de Estudos e Pesquisas em Educação Especial na Amazônia (UEPA) e do Grupo de Estudos e Pesquisas Interdisciplinares em Diversidade e Inclusão (UNAMA). Brasil. Orcid: https://orcid.org/0000-0003-4250-0532. E-mail:
} ped_igorbelo@hotmail.com 


\title{
NARRATIVES AND REPRESENTATIONS ABOUT THE DEAF IN VIRTUAL \\ TECHNOLOGIES: Videographic analysis on the youtube ${ }^{\circledR}$ website
}

\begin{abstract}
This article aims to analyze the narratives contained in different types of Brazilian videos posted on the YouTube ${ }^{\circledR}$ website which talk about deaf subjects regarding the representations conveyed about them, whether they are based on narratives of difference or disability. The study approach is qualitative and it is an exploratory research through documentary analysis of 08 videos selected through internet search using the term "deaf mute", on July 12, 2019. It was found 543 videos related to the search term with different dates of posts, referring to the period 2018 and 2019 , of these 204 presented in the title the term "deaf mute" which we categorized as religious context videos, jokes and reports. From the results of the analysis is observed that the narratives about the Deaf are based on a representation of deafness as a disease and the Deaf as incapable persons.
\end{abstract}

Keywords: Narratives. Representations. Deaf. Virtual technology.

\section{NARRATIVAS Y REPRESENTACIONES SOBRE LAS PERSONAS SORDAS EN TECNOLOGÍAS VIRTUALES: análisis de videos en el sitio web de YouTube®}

\section{RESUMEN}

El artículo en cuestión tiene como objetivo analizar las narrativas contenidas en diferentes tipos de videos brasileños publicados en el sitio web de YouTube ${ }^{\circledR}$, que hablan de personas sordas; con atención a las representaciones que se transmiten sobre ellas, si se basan en narrativas de diferencia o discapacidad. El abordaje del estudio es cualitativo y constituye una investigación exploratoria, mediante el análisis documental de 08 videos seleccionados mediante búsqueda en internet, utilizando el término "sordomudo", el 12 de julio de 2019, encontrándose 543 videos, relacionados con el término de búsqueda, con diferentes fechas de publicación, referidos al período de 2018 y 2019, de estos 204 presentaron en el título el término "sordomudo", los cuales categorizamos como videos de contexto religioso, contexto religioso, chiste y reportajes. A partir de los resultados del análisis, se observa que las narrativas sobre los sordos se basan en una representación de la sordera como enfermedad y del sordo como personas incapacitadas.

Palabras clave: Narrativas. Representaciones. Sordo. Tecnología virtual.

\section{INTRODUÇÃO}

Ortigo em questão contextualiza-se no âmbito das discussões sobre as narrativas veiculadas nas tecnologias virtuais sobre os sujeitos Surdos ${ }^{4}$, ao considerar que essas narrativas projetam representações que podem revelar

\footnotetext{
${ }^{4}$ Surdos com "S" maiúsculo por entender esses sujeitos pela diferença com respeito a sua condição linguística e cultural.
} 
como a sociedade compreende esse sujeito, e com base nos referenciais teóricos em estudos surdos (SKLIAR, 2009; PERLIN, 1998, 2000, 2003; LUNARDI, 1998, 2003; LANE, 1992; VIEIRA-MACHADO, 2010), essas representações se diferenciam em momentos históricos distintos, que os definem ora como sujeitos patológicos e incapazes, a surdez como doença; ora como sujeitos narrados como parte de um grupo minoritário, com especificidades linguísticas que devem ser respeitadas e valorizadas, a surdez como diferença.

As narrativas, segundo Barthes (1971) se apresentam em diferentes gêneros, sustentadas por diferentes linguagens, sejam elas articuladas, orais ou escritas, por imagens fixas ou móveis, gestos ou misturas ordenadas de todas as substâncias. E, "sob estas formas quase infinitas, a narrativa está presente em todos os tempos, em todos os lugares, em todas as sociedades; a narrativa começa com a própria história da humanidade" (BARTHES, 1971, p.18 apud SANTAELLA, 2001, p. 317). Deste modo, o ato de narrar faz parte da existência humana, "vivemos as nossas relações conosco mesmos e com os outros narrando. Nossa vida é uma teia de narrativas na qual estamos enredados" (MOTTA, 2013, P.17).

As representações sociais de acordo com as análises de Moscovici constituem em uma "formação de um outro tipo de conhecimento adaptado a outras necessidades, obedecendo a outros critérios, num contexto social preciso" (MOSCOVICl, 1978, p. 24). Assim, as representações sociais se formam principalmente quando as pessoas estão expostas às instituições, aos meios de comunicação de massa e à herança históricocultural da sociedade. O saber do senso comum é valorizado, torna o não familiar em familiar, desta forma, o saber do cotidiano do sujeito é considerado, efetua-se o rompimento com a supremacia do conhecimento científico. Nas palavras de Moscovici (2003, p.28), as representações sociais se constituem como:

Um conjunto de conceitos, preposições e explicações criado na vida cotidiana no decurso da comunicação interindividual. São o equivalente, na nossa sociedade, dos mitos e sistemas de crenças 
das sociedades tradicionais, podem ainda ser vistas com a versão contemporânea do senso comum.

Jovchelovitch (1997) se refere as representações sociais como uma estratégia desenvolvida por atores sociais "para enfrentar a adversidade e a mobilidade de um mundo que, embora pertença a todos, transcende a cada um individualmente" (p.42).

Deste modo, optamos pelo site do YouTube ${ }^{\circledR}$, para desenvolver este estudo, por se constituir de um espaço no ambiente virtual, na rede da internet, onde podemos acessar diferentes assuntos em tempo limitado, mas que apesar de ser informativo, disseminador de cultura também pode incentivar processos que alteram a noção de respeito, ética e moral, valores estes cultivados por muitas culturas (RODRIGUES, 2015).

Diante do exposto, apresentamos como objetivo geral deste estudo: analisar as narrativas contidas em diferentes tipos de vídeos brasileiros postados no site do YouTube ${ }^{\circledR}$, que falam sobre sujeitos Surdos com atenção as representações veiculadas sobre eles, se estão fundamentadas em construtos da diferença ou da incapacidade.

A abordagem do estudo é qualitativa, devido à possibilidade de compreender os significados e características do problema ou objeto de investigação e sua complexidade, que ainda, segundo Paulilo (1999) ela trabalha com valores, crenças, representações e opiniões para a compreensão dos fenômenos, caracterizados por significativo grau de complexidade.

Como procedimentos o estudo se constitui de uma pesquisa exploratória, por meio da análise documental de vídeos selecionados no site YouTube®, com o auxilio de algumas técnicas da Análise de Conteúdo proposta por Bardin (2011); a partir da busca na internet, onde podem ser acessados e compartilhados por qualquer pessoa em qualquer parte do mundo, de forma online.

Na selecão dos vídeos para as análises, no dia 12 de julho de 2019, utilizamos o termo "surdo mudo", na barra de pesquisas do site do YouTube®, por considerá-lo mais pertinente aos propósitos deste estudo, sendo 
encontrados 543 vídeos relacionados com o termo de busca, com diferentes datas de postagens, referentes ao período de 2018 e 2019, destes 204 apresentavam no título o termo "surdo mudo", porém selecionamos 08 vídeos, devido apresentarem narrativas que se coadunavam com o objetivo do estudo, que categorizamos como vídeos de contexto religioso, de piadas, e de reportagens. Os vídeos não utilizados tinham conteúdos informativos, musicais, de propagandas comerciais; alguns com conteúdos repetidos com títulos diferentes e outros sem referência aos surdos.

Neste estudo trataremos inicialmente sobre a surdez e os surdos, conceitos e representações, em seguida, o debate sobre as tecnologias virtuais e as análises e discussões sobre as narrativas e representações sobre os surdos. Por fim, as considerações finais.

\section{A SURDEZ E OS SURDOS: conceitos e representações}

Para iniciar as discussões deste estudo sobre as narrativas e representações sobre os sujeitos Surdos veiculadas nas tecnologias virtuais, necessário se faz apresentar alguns aspectos conceituais e de representações construídos socialmente sobre eles para assim realizar as devidas explanações acerca da temática.

Segundo Lima (2009) os surdos apresentam especificidades inerentes às condições da surdez, dentre outras as linguísticas, que se evidenciam e se diferenciam pelos processos comunicacionais, que se realizam por meio de uma língua de modalidade visuoespacial, a língua de sinais, e também pela leitura de mundo que se dão pelas experiências visuais.

Em consonância com a definição acima, no Decreto Federal $N^{\circ}$. $5626 / 2005$ as pessoas surdas são conceituadas como aquelas que, devido à perda auditiva, apreendem o mundo por meio das experiências visuais, manifestando suas especificidades culturais principalmente pelo uso da língua de sinais. Para tanto, a identificação do surdo situa-se no âmbito das experiências visuais. A surdez, neste contexto, é reconhecida como diferença entre surdos e ouvintes. 
A surdez comumente é apresentada ora como uma diferença entre surdos e ouvintes, construto sócioantropológico; ora como uma limitação que impede o desenvolvimento global da pessoa Surda, tendo como parâmetro o modelo ouvinte, construto clínico-terapêutico.

Giordani $(2012$, p.139) afirma que nas discussões atuais destacam-se duas formas de representar os Surdos e a surdez, o modelo clínicoterapêutico:

(...) que considera o surdo como um deficiente auditivo, precisando ter sua deficiência removida através de terapias da fala e sessões de oralização. Esses procedimentos são utilizados com o fim de tornar o mais parecido possível com as pessoas ouvintes. E isso só pode ocorrer com o mascaramento da surdez, com a proibição da língua visual que os surdos utilizam, com a sua medicalização através da leitura labial e do aprendizado da emissão vocal de algumas poucas palavras sem sentido para os surdos.

No modelo socioantropológico, a surdez é compreendida "(...) a partir de uma leitura cultural, na qual os surdos, em sua comunidade, agrupam-se para discutir e opinar sobre suas vidas, não apenas porque tem em comum o fato de não ouvirem, mas por serem sujeitos visuais" (GIORDANI, 2012, p.139).

Nos mais diversos espaços sociais, historicamente, as narrativas sobre a surdez, se delineiam e se cristalizam em pressupostos, atitudes e saberes, pautados nesses dois modelos. Mas, é inegável a história de vida diferenciada dos Surdos por conta da essência 'gestual' de sua língua, de modalidade visual-espacial, portanto, "uma visão de mundo distinto dos ouvintes, que falam uma língua de modalidade oral, cuja substância é o 'som'"(SALLES, 2005). Como em Felipe (2001 apud SALLES, 2005), quando afirma que os Surdos possuem uma forma singular de apreender o mundo que gera valores, comportamentos comuns compartilhados e tradições sócio-interativas, distintas dos ouvintes.

Diante disto, a língua de sinais para os Surdos no dizer de Poche (1989 apud SANTANA; BERGAMO, 2005, p. 572), "é um instrumento que serve a 
linguagem para criar, simbolizar e fazer circular sentido, é um processo permanente de interação social".

No Brasil, a comunidade surda usa a Língua Brasileira de Sinais - Libras, assegurada pela Lei $n^{\circ}$ 10.436/02, reconhecida como língua, com estrutura gramatical própria e sistema linguístico de natureza visual-motora.

Conforme Ferreira-Brito (1997), a Libras apresenta uma gramática a partir de elementos constitutivos das palavras ou itens lexicais e de um léxico (conjunto das palavras de uma dada língua) que se organizam em termos morfológicos, sintáticos e semânticos, orientados por princípios básicos gerais, específicos das línguas visuais espaciais e com estruturas linguísticas que possibilitam a produção infinita de construções a partir de um número finito de regras. $E$, também, se constituem de elementos pragmáticos convencionais que estes "permitem a geração de implícitos sentidos metafóricos, ironias e outros significados não literais" (FERREIRA-BRITO,1997, p. 23).

Deste modo, a língua de sinais, é a língua que o Surdo pode dominar plenamente e atende de forma eficaz as suas necessidades comunicacionais e cognitivas, de modo independente da língua oral.

\section{TECNOLOGIAS VIRTUAIS}

Conforme Gouveia (2004) a sociedade da informação se baseia nas tecnologias de informação e comunicação que compreendem a aquisição, - armazenamento, o processamento e, também, a distribuição da informação por meios de distintos meios como o rádio, a televisão, o telefone dentre outras vias eletrônicas. E, ressalva o autor que essas tecnologias ao serem utilizadas em diversos contextos sociais, econômicos e políticos pelas pessoas, criam uma nova comunidade local e global, a Sociedade da Informação. Sendo que esse processo de divulgação e difusão da informação resulta do veloz avanço tecnológico que a sociedade atual presencia.

$\mathrm{Na}$ definição de Werthein (2000), a Sociedade da informação se constitui "do novo paradigma técnico-econômico", em substituição ao 
complexo conceito de "sociedade pós-industrial", vinculada à expansão do sistema capitalista desde os anos 80 , na qual se explica as privatizações e a ruptura do modelo de contrato social entre o capital e trabalho. Essa mudança representa o surgimento de um novo paradigma: "O da tecnologia da informação, que expressa a essência da presente transformação em sua relação com a economia e a sociedade" (WERTHEIN,2000, p.72).

Gouveia (2004, p.2) afirma que: "numa Sociedade de Informação, as pessoas aproveitam as vantagens das tecnologias em todos os aspectos das suas vidas: no trabalho, em casa e no lazer", mas chama atenção ao dizer que: "não é a tecnologia, apesar de tudo, o elemento crucial, mas sim o que esta pode potenciar nas relações entre pessoas e pessoas e organizações".

O ciberespaço é o espaço da comunicação que se realiza por meio das redes de computadores interconectadas de forma global pela internet e, apresenta diferentes aplicações e maneiras de comunicação, mas a função primeira é realizar transmissões de dados digitalizados e criptografados.

As páginas da web estão inseridas no ciberespaço, como documentos hipermidiáticos, sendo aqueles que integram várias mídias em um suporte computacional que se constituem de um site e o acesso é realizado por meio de um endereço eletrônico requisitado em um programa de navegação. Os sites interativos, como o Instagram, o Facebook, e o YouTube®, são exemplos de ciberespaços. E, este estudo se propôs a pesquisar as narrativas e representações sobre o sujeito Surdo na web YouTube®, cujo endereço é https://www.youtube.com.

De acordo com Aguiar; Rosário (2008 apud RODRIGUES, 2015, p.11):

○ YouTube $\AA^{\circledR}$, um site agregador de conteúdos e instrumento constituinte desta grande rede que é a Internet, pode ser considerado, hoje, o maior conglomerado de redes de comunicação e empregado como objeto de aproximação por pessoas de todas as idades no contexto da cibercultura, visto que ele é um dos instrumentos mais utilizados quando se deseja visualizar ou postar determinado vídeo, caracterizado por suas possibilidades de grande armazenamento. 
Destarte, emerge a indagação: qual representação sobre os Surdos esta sendo divulgada no contexto das tecnologias virtuais em diferentes vídeos postados no site do YouTube? São narrativas pautadas na diferença ou na deficiência? Apesar dos avanços nas discussões sobre as especificidades das pessoas surdas, ainda recorrem dúvidas quanto às representações passadas pela mídia. Daí a relevância da proposição desta discussão sobre as narrativas e representações sobre elas divulgadas pelas tecnologias virtuais (YouTube $\AA$ ), com a perspectiva de oferecer mais subsídios para se avançar em novas reflexões que possam compreender essas pessoas nas suas singularidades.

\section{NARRATIVAS E REPRESENTAÇÕES SOBRE OS SURDOS: análises e discussões}

Os vídeos estão organizados em Quadros, identificados como VCR, para os Vídeos de Contexto Religioso, VP para os Vídeos de Piadas e VR para os Vídeos de Reportagens, seguidos da numeração 1, 2 ou 3 (de acordo com a quantidade selecionada para cada categoria) e respectivos títulos e sínteses, de acordo com a nossa compreensão sobre o conteúdo, para discorrer às análises e discussões.

Optamos iniciar pelos Vídeos de Contexto Religioso (VCR), dispostos no Quadro 1, mas antes de qualquer análise é oportuno considerar que a trajetória histórica e social das pessoas Surdas apresenta diferentes atitudes dispensadas a elas, conforme a concepção de ser humano predominante em cada época, que segundo Slomski (2012) essas concepções resultaram em diversas práticas e relações que vão do extermínio, da segregação, da classificação, dentre outras, até a valorização do humano que existe em cada uma delas. Mas, ressalvamos que determinadas formas de representar o Surdo na contemporaneidade, tendo como base este estudo, ainda são resultados da reprodução que herdamos de distintos períodos históricos que precisam ser refletidos, devido à inadequação na compreensão das singularidades dos Surdos, em especial, a linguística. Vejamos a disposição do Quadro 1. 
Quadro 1: Vídeos de Contexto Religioso (VCR)

\begin{tabular}{|c|c|c|}
\hline Vídeo & Título & Síntese \\
\hline VCR 1 & $\begin{array}{l}\text { "Milagre de Deus, } \\
\text { surdo e mudo ouve } \\
\text { e fala pela primeira } \\
\text { vez-Ap.Onório" }\end{array}$ & $\begin{array}{l}\text { Numa manifestação religiosa uma mãe } \\
\text { que apresenta seu filho com um cartaz } \\
\text { "ele é surdo e mudo" na presença do líder } \\
\text { religioso, que começa a fazer } \\
\text { massagens no ouvido e na boca do } \\
\text { jovem, depois pede para ele repetir } \\
\text { algumas palavras e números, o jovem } \\
\text { repete com uma certa dificuldade na } \\
\text { fala, e o líder religioso diz para a mãe } \\
\text { treinar a fala dele em casa, porque o } \\
\text { "demônio que fazia ele ser surdo e mudo } \\
\text { já saiu dele". }\end{array}$ \\
\hline VCR2 & $\begin{array}{l}\text { "Menino surdo e } \\
\text { mudo...sai falando e } \\
\text { ouvindo após ser } \\
\text { mergulhado } \\
\text { água pa } \\
\text { colegas" }\end{array}$ & $\begin{array}{l}\text { Apresenta uma imagem de uma mulher } \\
\text { com um véu e decorre um áudio } \\
\text { contando uma história, onde crianças } \\
\text { brincavam de batismo e uma delas era } \\
\text { um menino surdo, que ao chegar em } \\
\text { casa falou para mãe "olha o que fizeram } \\
\text { comigo estou todo molhado", a mãe } \\
\text { emocionada começou a chorar e a } \\
\text { pessoa que acompanhava o menino } \\
\text { explicou o que tinha acontecido e a mãe } \\
\text { respondeu: "eu não estou chorando por } \\
\text { ele está molhado, mas porque meu filho } \\
\text { era surdo e mudo". }\end{array}$ \\
\hline VCR3 & $\begin{array}{l}\text { "Não seja surdo e } \\
\text { mudo!" }\end{array}$ & $\begin{array}{l}\text { Retrata um padre que diz em sua } \\
\text { pregação que "aquele que não } \\
\text { consegue ouvir como nós, as palavras são } \\
\text { só balbuciadas, você nunca vai ver um } \\
\text { surdo falando bonito, porque aquele que } \\
\text { não ouve não fala de uma forma } \\
\text { adequada. Um surdo profundo vai ser } \\
\text { alguém que também vai ser um mudo, } \\
\text { porque não vai saber falar". }\end{array}$ \\
\hline
\end{tabular}

Fonte: elaborado pelos autores.

Desta feita, observamos que no conteúdo do VCR1 ainda se reproduz representações que explicam a surdez como manifestações demoníacas, como na Idade Média, pois a Igreja considerava o Homem a imagem e semelhança de Deus, mas de um Deus perfeito, e se ao nascer, a criança apresentasse alguma deficiência, era comparada à imagem do diabo e, em consequência, era vítima constante de perseguição e de julgamento sem precedentes, sendo comuns sessões de exorcismo (MAZZOTTA, 2001). 
No VCR2 o conteúdo revela uma narrativa constituída pela representação da surdez como doença possível de ser curada por intervenção divina. Slomski (2012) diz que até mesmo na Bíblia, já se observava concepções negativas em relação à surdez, pois a voz e o ouvido eram exaltados como única forma de falar e ouvir a palavra de Deus, sendo assim os Surdos eram desumanizados por conta da sua limitação auditiva.

O VCR3 apresenta afirmações fundamentadas na concepção de surdez como deficiência e incapacidade a partir de uma falta, de um dano, de um prejuízo, pois sendo Surdos nunca poderão falar adequadamente. Assim, '"Não ter a fala' pressupõe, em uma sociedade oral, a mudez; dito de outro modo, pressupõe 'ausência' de pensamento ou, pelo menos, pressupõe o que o surdo não tem o que dizer" (LOPES, 2007, p.51).

Desta forma, as especificidades da pessoa surda são ignoradas, mas conforme Giordani (2012) é necessária a discussão sobre as formas de entendimento da surdez como anormalidade, na direção de entendê-la a partir da diferença como uma "construção histórica e social, efeito de conflitos sociais, ancoradas em práticas de significação e de representações compartilhadas entre os surdos (SKLIAR, 1998, p.13 apud GIORDINI, 2012, p. 140). Isso significa compreender que surdez resulta em uma forma de ser e estar no mundo e não como doença que incapacita o Surdo.

Mas, deflagra-se a persistência numa representação estereotipada dos Surdos, como afirma Dorziat (2011, p.8), que:

No decorrer da história, os surdos têm visto suas identidades serem construídas por meio de discursos recheados de estereotipias, nos quais a deficiência auditiva surge como um aspecto definidor de todas as suas (im)possibilidades. As infinitas capacidades humanas de estabelecer contatos, relações e de construir caminhos múltiplos são ignoradas, ratificando-se o binômio normal/deficiente, como possibilidades opostas.

Por isso, no campo educacional essas representações do sujeito Surdo foram e, talvez, ainda sejam na atualidade reflexo das práticas que impõem a eles a "normalidade" por meio da imposição da oralidade, assim, "a superação da condição da surdez, através do aprendizado da língua oral - 
da medicalização da surdez", para que sejam aceitos e incluídos socialmente, e desta forma adquirirem "valores e padrões culturais dos que ouvem e falam" (THOMA, 1998, p. 127).

A abordagem oralista, como único meio de inclusão educacional e social dos Surdos, cujo método requeria estratégias de treinos exaustivos para que pudessem fazê-los emitirem voz e lerem os lábios de seus interlocutores, mais precisamente no final do século XIX, se consagrou (e ainda se consagra?) na história da educação desses sujeitos, na qual eram concebidos como inábeis de comunicação e, por conseguinte, "incapazes de pensamento - condição atribuída ao humano" (LOPES, 2007, p.58).

Quadro 2: Vídeos de Piadas (VP)

\begin{tabular}{|c|c|c|}
\hline Vídeo & Título & Síntese \\
\hline VP1 & $\begin{array}{l}\text { "O surdo e mudo no } \\
\text { tráfico de drogas" e } \\
\text { "Surdo/Mudo } \\
\text { discursando na } \\
\text { política" }\end{array}$ & $\begin{array}{l}\text { Uma dupla de humorista conta um } \\
\text { "causo", onde apresentam um "surdo } \\
\text { mudo", que fora usado por traficantes } \\
\text { para esconder o dinheiro da venda das } \\
\text { drogas, como estratégia para não serem } \\
\text { descobertos pelo grupo rival. Mas, ao ser } \\
\text { interrogado e ameaçado de morte, com } \\
\text { a presença de um intérprete, o } \\
\text { "mudinho" conta onde escondeu o } \\
\text { dinheiro, porém o intérprete manipula a } \\
\text { fala do surdo, afirmando que ele diz não } \\
\text { saber de nada, mesmo o surdo } \\
\text { confessando a verdade, e o surdo é } \\
\text { assassinado pelos traficantes. "Resultado: } \\
\text { surdo e mudo saiu de cena". }\end{array}$ \\
\hline VP2 & $\begin{array}{l}\text { "Surdo/Mudo } \\
\text { discursando } \\
\text { política" }\end{array}$ & $\begin{array}{l}\text { Dois humoristas contam uma piada sobre } \\
\text { a inauguração de um viaduto por um } \\
\text { político, que ao discursar observa na } \\
\text { plateia um homem que o aplaudia com } \\
\text { muita empolgação ao saber que se } \\
\text { tratava de um fã lhe concede a palavra. } \\
\text { o homem era surdo e se manifestou por } \\
\text { meio de uma sequência de gestos, } \\
\text { considerados obscenos pelo político, } \\
\text { mas que ao serem interpretados tinham } \\
\text { outros significados. }\end{array}$ \\
\hline
\end{tabular}

Fonte: elaborado pelos autores. 
Nos Vídeos acima (VP1 e VP2), são reforçadas formas estereotipadas sobre os Surdos e sua língua, e há a afirmação, nos conteúdos das sínteses apresentadas (Quadro 2), de que eles são facilmente manipulados e enganados, meramente pelo fato de serem Surdos (VP1). A referência aos intérpretes da língua de sinais, como a "voz" do Surdo pode obscurecer uma crença, numa afirmação do senso comum recorrente de que os sujeitos Surdos não têm língua (GESSER, 2009). E, ainda coloca o profissional intérprete da língua de sinais numa situação antiética, em discordância com a Lei No 12.319 de 2010 que regulamenta essa profissão, no Art. $7^{\circ}$ estabelece que esse profissional deve exercer seu ofício "com rigor técnico, zelando pelos valores éticos a ela inerente, pelo respeito à pessoa humana e à cultura do surdo".

No VP2 observamos o desconhecimento sobre a língua de sinais e a situa como simples realizações de gestos, mímicas e pantomimas. Gesser (2009) diz que nessa forma de entendimento equivocado sobre a língua de sinais está encoberto um preconceito muito grave, que esta além das discussões sobre a legitimidade linguística da língua de sinais, mas também:

(...) a ideia que muitos ouvintes têm sobre os surdos: uma visão embasada na anormalidade, segundo a qual o máximo que o surdo consegue expressar é uma forma pantomímica indecifrável e somente compreensível entre eles. Não à toa, as nomeações pejorativas anormal, deficiente, débil mental, mudo, surdo mudo, mudinho, tem sido equivocadamente atribuídas a esses indivíduos (GESSER, 2009, p.21).

A língua de sinais apresenta todos os universais linguísticos de qualquer outra língua, no caso da Libras, é a segunda língua oficial do Brasil, dos Surdos urbanos brasileiros, conforme a Lei $n^{\circ} 10.436$ de 2002, e por meio dessa língua, qualquer conceito mesmo abstrato pode ser comunicado, e não reconhecê-la como língua pode-se cometer uma forma de preconceito linguístico, com afirmações infundadas como a de considerá-la limitada ou mesmo achar que se trata simplesmente de mímicas ou gestos, com desdobramentos que podem inferir que os Surdos não tem língua. 
Skliar (1998) chama a atenção para o fato da Libras, comprovadamente, cumprir todas as funções de uma língua natural, mas ainda é desvalorizada por ser tomada como simples pantomimas, por pessoas desinformadas. Perlin (2005) reitera que a língua de sinais é própria das pessoas surdas, não é uma anormalidade, como pensam algumas pessoas desinformadas, que as comparam com a linguagem dos macacos.

Quadro 3: Vídeos de Reportagem (VR)

\begin{tabular}{|l|l|l|}
\hline Vídeo & \multicolumn{1}{|c|}{ Título } & Síntese \\
\hline VR1 & $\begin{array}{l}\text { "Entrevista com a } \\
\text { testemunha surdo } \\
\text { e mudo" }\end{array}$ & $\begin{array}{l}\text { Apresenta um repórter entrevistando um jovem } \\
\text { surdo. Ele faz uma introdução dizendo que o jovem } \\
\text { vai relatar sobre o assalto que matou um policial, } \\
\text { mas que ele tem uma deficiência: "é surdo e } \\
\text { mudo", mas que vai tentar se comunicar com o } \\
\text { jovem mesmo não sabendo a língua de sinais", e o } \\
\text { jovem se expressa por meio de sons e movimentos } \\
\text { corporais. }\end{array}$ \\
\hline VR2 & $\begin{array}{l}\text { "Homem surdo } \\
\text { mudo que usou } \\
\text { bilhete para } \\
\text { assaltar um posto } \\
\text { de combustíveis érter informa que o "surdo mudo" que } \\
\text { solto" }\end{array}$ & $\begin{array}{l}\text { assaltou um posto de combustível usando um } \\
\text { bilhete foi detido, mas já havia sido solto e diz que } \\
\text { o crime chamou atenção não pela crueldade, } \\
\text { mas pela criatividade. }\end{array}$ \\
\hline VR3 & $\begin{array}{l}\text { "Mudo e surdo } \\
\text { tem raiva de } \\
\text { botão" }\end{array}$ & $\begin{array}{l}\text { Apresenta um repórter entrevistando um senhor } \\
\text { surdo, querendo que ele afirme que tem raiva de } \\
\text { botão. O senhor emite alguns sons e sorri, } \\
\text { demonstra não entender a intenção e nem a } \\
\text { pergunta do repórter. Mas o repórter afirma que } \\
\text { todo surdo-mudo tem raiva de botão e não sabe o } \\
\text { motivo. }\end{array}$ \\
\hline
\end{tabular}

Fonte: elaborado pelos autores.

Diante dos vídeos selecionados e categorizados como de reportagem dispostos nas respectivas sínteses dos seus conteúdos, Quadro 3, observamos que as representações do sujeito Surdo têm as mesmas acepções dos anteriores, somadas a requintes de sarcasmos, que colocam os Surdos em situações difíceis, consideradas em nosso ponto de vista como humilhantes. Strobel (2008, p. 22) afirma que os ouvintes "vêem os surdos com curiosidade e, as vezes zombam por eles serem diferentes". Sendo essa forma de 
representar os Surdos baseadas fortemente no ouvintismo, que dominou historicamente no âmbito do "modelo clínico e demonstra as táticas de atitude reparadora e corretiva da surdez, considerando-a como defeito e doença".

O Ouvintismo na busca de uma compreensão, nas palavras de Skliar (1998, p.15):

Trata-se de um conjunto de representações dos ouvintes, a partir da qual o surdo está obrigado a olhar-se e narra-se como se fosse ouvinte. Além disso, é nesse olhar-se, e nesse narrar-se que acontecem as percepções do ser deficiente, do não ser ouvinte; percepções que legitimam as práticas terapêuticas habituais.

O VR1 demonstra a situação constrangedora que o Surdo é exposto pelo repórter, com total desrespeito ao jovem Surdo, e reforça as falas de Goldfeld (2002) ao relatar que lá na antiguidade, os surdos também eram percebidos como pessoas incapazes e doentes, geralmente, eram concebidas somente pelos aspectos negativos, enfrentando todo tipo de preconceito, descrédito e piedade. A eles era negado o direito de participação ativa na sociedade.

Dentre outras narrativas que representam os Surdos de forma negativa ainda observamos aquelas que dizem que os Surdos são violentos, agressivos como se todos os surdos fossem iguais, como exemplo a referência feita no VR2, que já se esperava que o Surdo agisse com agressividade, e de outra feita que não considera o bilhete escrito pelo Surdo, como sua forma de comunicação na modalidade escrita da língua portuguesa. No VR3 a situação se evidencia na mesma linha e intenção dos demais vídeos, expondo o Surdo ao constrangimento.

A produção escrita dos Surdos apresenta singularidades que perpassam por diferentes questões, dentre outras, o pouco conhecimento deles sobre a língua portuguesa, já que o ensino dessa língua demanda metodologias focadas nas especificidades deles, numa proposta de educação bilíngue, que entende a língua de sinais como a primeira língua a ser adquirida, e a segunda língua a modalidade escrita da língua portuguesa (GESUELI, 2012), constituindo-se de um ensino totalmente visual. 
E, O atravessamento das línguas, já que os Surdos falam uma língua de modalidade visuoespacial, mas a continuidade escrita é por meio da língua portuguesa, então são duas línguas em interatividade, porém com estruturas distintas e independentes. Por isso, que a escrita dos Surdos apresenta características diferenciadas, "decorrentes da interferência da interlíngua do sujeito surdo nas regras da língua portuguesa e, principalmente, da falta de um projeto escolar que levasse em conta a surdez como diferença" (GESUELI, 2012, p.177).

Diante do exposto, no VR2, o desconhecimento da escrita do Surdo e, sobretudo, colocar essa escrita como uma forma meramente criativa de cometer um delito e não como um meio comunicacional traduz uma forma de preconceito as especificidades surdas.

O imaginário social em relação à expressão Surdo é carregado de estigmas e de deficiência. Isso fica claro nas palavras de Perlin (1998, p.54):

O estereótipo sobre o surdo jamais acolhe o ser surdo, pois o imobiliza a uma representação contraditória, a uma representação que não conduz a uma política da identidade. O estereótipo faz com que as pessoas se oponham, às vezes disfarçadamente, e evite a construção da identidade surda, cuja representação é o estereótipo da sua composição distorcida e inadequada.

De acordo com Paddy Ladd (2013), as representações que situam os Surdos como incapazes e deficientes se contextualizam na "Grande Narrativa" do século XX, onde a história dos Surdos eram contadas e registradas pelos ouvintes, e eram percebidos como seres inferiores, na base moral e comunicacional. Os próprios Surdos passaram a acreditar que não tinham história própria e legítima. Na posição inversa inaugura-se a contra narrativa que se fundamenta na Surdidade, "uma vez que a preocupação das comunidades Surdas, tal como de outras comunidades minoritárias, é em estabelecer claramente as suas tradições face às energias assimilatórias esmagadoras, etnocidas, contra as quais foram obrigadas a lutar durante séculos" (PADDY LADD, 2013, p.43).

Para Vieira-Machado (2010) é urgente situar as narrativas sobre os Surdos, na pós-modernidade, em representações que se direcionem às 
questões políticas, identitárias, linguísticas e culturais desses sujeitos, que refutem representações estereotipadas de incapacidade, de doença, de modelos audiológicos, ou seja, baseadas em representações clínicas e terapêuticas. E, que se oponha as ideias presentes nos últimos 100 anos sobre as práticas ouvintistas quando essas se difundem por meio de estratégias colonizadoras, e as problematizam desnudando seus efeitos desvastadores sobre os Surdos (DORZIAT, 2011). Deste modo, a contra narrativa ou contra discurso trabalha a favor da derrocada do ouvintismo, que produziu/produz o "holocausto linguístico, cognitivo e cultural em que viveram os surdos" (VIEIRA-MACHADO, 2010, p.50).

Diante dessas discussões e análises consideramos, então, a necessidade de um novo olhar sobre os Surdos que reconheça, respeite e valorize suas diferenças. Que se contraponha as representações veiculadas nos vídeos selecionados e analisados neste artigo, que apesar de atuais ainda estão carregados de ideias e práticas ouvintistas.

\section{CONSIDERAÇÕES FINAIS}

O estudo em questão, com o objetivo de analisar as narrativas contidas em diferentes tipos de vídeos brasileiros postados no site do YouTube ${ }^{\circledR}$, sobre os Surdos, observamos representações recorrentes nos vídeos selecionados, inscritas em construtos clínico-patológicos sobre eles, na suposição de que são pessoas doentes, limitados, incapazes, que precisam ser tratadas, exorcizadas, práticas que se justificam pela ignorância, pelo deboche e desrespeito a integridade da pessoa Surda.

A partir das análises e discussões sobre os dados produzidos, conduziram-nos à compreensão, com base na teoria das representações sociais, quando os Surdos são nomeados de "surdos-mudos", "mudinhos" e "deficientes", opera-se a categoria da classificação, de forma a estabelecer uma relação negativa em relação a eles, de exclusão, por não estarem enquadrados numa determinada ordem, padrão ou modelo que julgam serem adequados e aceitos socialmente.

Outra questão evidenciada no estudo está na crença que a 
"normalização" dos Surdos está na imposição da oralidade, na ouvintização desses sujeitos, mesmo com as avançadas discussões na contemporaneidade, que dão conta da importância da língua de sinais no desenvolvimento global deles. E, que eles, os Surdos, são livres para fazerem suas escolhas dentre outras, as comunicacionais.

Compreendemos a emergência de desconstruir narrativas sobre os Surdos que se baseiam em representações, que limitam e incapacitam esses sujeitos, e pautá-las por uma nova perspectiva que possa de fato romper com os modelos de deficiência e de doença, que se direcionem, portanto, para outras vias de representações que considerem as diferenças identitárias, linguísticas e os processos culturais dos Surdos, ou seja, em representações sócioantropológicas.

Consideramos que este estudo oportuniza a reflexão sobre a situação dos Surdos na atualidade e, principalmente as representações que estão sendo veiculadas nas tecnologias virtuais, de amplo alcance de todos, que podem influenciar compreensões negativas sobre eles. Mas, também, que este possa contribuir para as mudanças urgentes na construção de uma nova história sobre esses sujeitos, com o reconhecimento e respeito à sua diferença, à valorização da sua língua e libertá-los de qualquer forma de ouvintismo.

\section{REFERÊNCIAS}

BARDIN, L. Análise de conteúdo. Tradução de L. A. R. Augusto. 1. ed. rev. e ampl. Lisboa: Edições 70, 2011.

DORZIART, A. (org.). Estudos Surdos: diferentes olhares. Porto Alegre: Mediação, 2011.

FERREIRA-BRITO, L. Língua de Sinais - LIBRAS. In: BRASIL. Secretaria de

Educação Especial. Brasília: SEESP. 1997.

GESUELI, Z. M. A escrita como fenômeno visual nas práticas discursivas de alunos surdos. In: LODI, A. C. B.; DORZIAT, A.; FERNANDES, E. (orgs.).

Letramento, Bilinguismo e Educação de Surdos. Porto Alegre: Mediação, 2012. 
GESSER, A. LIBRAS? que língua é essa?: crenças e preconceitos em torno da língua de sinais e da realidade surda. São Paulo: Parábola Editorial, 2009.

GIORDANI, L. F. Encontros e desencontros da língua escrita. In: LODI, A. C. B.; DORZIAT, A.; FERNANDES, E. Letramento, bilinguismo e educação de surdos. Porto Alegre: Mediação, 2012.

GOUVEIA, L. M. Sociedade da informação: Notas de contribuição para uma definição operacional. 2004. Disponível em:

http://www2.ufp.pt/ Imbg/reserva/lbg_socinformacao04.pdf. Acesso: 15 de agosto de 2019.

GOLDFELD, M. A criança surda: linguagem e cognição numa perspectiva sócio-interacionista. 2 ed. São Paulo: Plexus Editora, 2002.

JOVCHELOVITCH, S. Vivendo a vida com os outros: intersubjetividade, espaço público e representações sociais. In: GUARESCHI, P.; JOVCHELOVITCH, S.

(Orgs.). Textos em Representações Sociais. Petrópolis: Vozes, 1997.

LIMA, K. S. C. Educação de surdos no contexto amazônico: um estudo da variação linguística na Libras. (Dissertação de Mestrado) - Universidade do Estado do Pará, Belém, 2009.

Lei Federal 12.319, de $1^{\circ}$ de setembro de 2010 - Profissão de Tradutor e Intérprete Libras. Disponível em:

www.portaldeacessibilidade.rs.gov.br > legislacao. Acesso em: 25 de agosto de 2019.

LOPES, M. C. Surdez e educação. Belo Horizonte: Autêntica, 2007.

MAZZOTA, M.J. S. Educação Especial no Brasil: Histórias e Políticas Públicas. 3a ed., São Paulo: Cortez, 2001.

MOSCOVICl, S. A Representação Social da Psicanálise. Rio de Janeiro: Zahar, 1978.

MOSCOVICl, S. Representações Sociais: investigações em psicologia.

Petropólis, Rio de Janeiro: Vozes, 2003.

PADDY LADD. Em busca da Surdidade: Colonização dos Surdos. Livro Original Understandig Deaf Culture. Tradução: Sintagma; Mariana Martini. 1 edição. Livraria especializada Ltda. Volume 1. 2013.

PAULILO, M. A. S. A pesquisa qualitativa e a história de vida. Serviço Social em Revista. Londrina, v.2, n. 2, p. 135-148, jul./dez.1999. Disponível em: <http://www.ssrevista.vel.br/n1v2.pdf>. Acesso em: 26 de julho de 2019. 
RODRIGUES, N. H. Tecnologias virtuais e análise videográfica: O YouTube® como recurso de pesquisa para compreensão sobre a imagem do idoso brasileiro. Programa de pós-graduação em desenvolvimento humano e tecnologias (Tecnologias nas dinâmicas corporais). UNESP. Dissertação de Mestrado. 2015. Disponível em:

<https://repositorio.unesp.br/bitstream/1 1449/126291/1/000841569.pdf>. Acesso em: 15 de julho de 2019.

SALLES, H.M.M.L. [e† al.]. Ensino da língua portuguesa para surdos: caminhos para a prática pedagógica. Brasília: MEC, SEESP, 2005.

SANTAELLA, L. Matrizes da linguagem e pensamento: sonora visual verbal: aplicações na hipermídia. Editora lluminuras, 2001.

SANTANA, A. P.; BERGAMO, A. Cultura e identidade surdas: encruzilhadas de lutas sociais e teóricas. Centro de Estudos Educação e Sociedade. Campinas, Vol. 26 n 91, p. 565-582, maio/agosto. 2005.

SERRANO, P. H. S. M. Cognição e interacionalidade através do YouTube. Disponível em: http://www.bocc.ubi.pt/pag/serrano-paulo-cognicaointeracionalidade-youtube.pdf. S/d. Acesso em: 25 de agosto de 2019.

SKLIAR, C. Um olhar sobre o nosso olhar acerca da surdez e das diferenças. In: A surdez: um olhar sobre as diferenças. Porto Alegre: Editora Mediação, 1998.

SKLIAR, C. (org.). A surdez: um olhar sobre as diferenças. 2. ed. Porto Alegre: Mediação, 1998.

SKLIAR, C. Atualidade da Educação Bilíngue para Surdos: processos e projetos pedagógicos. Editora Mediação. Porto Alegre, 2009.

THOMA, A. S. Surdo: esse "outro" de que fala a mídia. In: A surdez: um olhar sobre as diferenças. Porto Alegre: Editora Mediação, 1998.

VIEIRA-MACHADO, L.M.C. Ser bilíngue: estratégias de sobrevivência dos sujeitos surdos na sociedade contemporânea. In: VIEIRA-MACHADO, L.M.C.; LOPES, M.C.(orgs). Educação de surdos: políticas, língua de sinais, comunidade surda e cultura surda. Santa Cruz do Sul: EDUNISC, 2010.

WERTHEIN, J. A sociedade da informação e seus desafios. Ci.Inf., Brasília, v. 29, n.2, p.71-77, maio/ago. 2000. Disponível em:

www.scielo.br/scielo.php?pid=\$0100-

$19652000000200009 \&$ script=sci...tIng...Acesso em: 26/06/2019.

YOUTUBE. O surdo e mudo no tráfico de drogas. Disponível em: https://www.youtube.com/watch?v=FAdfNdCvu4Q. Acesso em: 12 de julho de 2019. 
YOUTUBE. Surdo/Mudo discursando na política. Disponível em:

https://www.youtube.com/watch? $v=$ bISYEeturDk. Acesso em: 12 de julho de 2019.

YOUTUBE. Milagre de Deus, surdo e mudo ouve e fala pela primeira vezAp.Onório. Disponível em:

https://www.youtube.com/watch?v=Qat7T_IZOAw. Acesso em: 12 de julho de 2019.

YOUTUBE. Menino surdo e mudo...sai falando e ouvindo após ser mergulhado na água por seus colegas. Disponível em:

https://www.youtube.com/watch? $v=\mid 3 n B U T 8 e c D 0$. Acesso em: 12 de julho de 2019.

YOUTUBE. Não Seja Surdo e Mudo! - Padre Cleberson Evangelista. Disponível em: https://www.youtube.com/watch?v=Zgx27U-uyxM. Acesso em: 12 de julho de 2019.

YOUTUBE. Entrevista com a testemunha surdo e mudo. Disponível em:

https://www.youtube.com/watch? $v=U U P O 2 b c P 5 G w$. Acesso em: 12 de julho de 2019.

YOUTUBE. Homem surdo mudo que usou bilhete para assaltar um posto de combustíveis é solto. Disponível em:

https://www.youtube.com/watch?v=SWXwS-B7oDw\&t=58s. Acesso em: 12 de julho de 2019.

YOUTUBE. Mudo e surdo tem raiva de botão. Disponível em:

https://www.youtube.com/watch?v=puDItDHCpkO. Acesso em: 12 de julho de 2019.

Recebido em: 10 de fevereiro de 2021.

Aprovado em: 12 de março de 2021.

Publicado em: 26 de março de 2021. 